\title{
UN ESPEJO DE AGUA CLARA: RAHEL VARNHAGEN COMO REFLEJO Y PROYECCIÓN DE HANNAH ARENDT (I)
}

\author{
Gabriela Rojo Silva ${ }^{1}$
}

Recibido: 03.06.2018 - Aceptado: 28.08.2018

\begin{abstract}
RESUMEN
Este artículo tiene como objetivo identificar en el libro de la temprana Hannah Arendt sobre la vida de Rahel Varnhagen - Rahel Varnhagen: The life of a Jewess - los primeros esbozos de los conceptos políticos que desarrollaría a lo largo de su vida dedicada a la teoría política, haciendo un seguimiento de su posterior aparición en diferentes obras. Se enfatiza el análisis aplicado de los conceptos de asimilación, paria y advenedizo. Se compara además las personas de Hannah Arendt y Rahel Varnhagen en cuanto a su origen judío y su condición de mujeres, tanto en la vida pública como en la privada y en la profundidad de su respectiva intimidad.
\end{abstract}

Palabras clave: Espacio, Paria, Asimilación, Identidad judía, Identidad femenina

\begin{abstract}
This paper intends to identify in the early Hannah Arendt's book on Rahel Varnhagen's life the first sketches of some of the political concepts that were developed throughout her life as political theorist. It includes a follow-up of these concepts as they appear in Arendt's different and later works and emphasizes the applied analysis of the concepts of assimilation, pariah and parvenu as well. Hannah Arendt and Rahel Varnhagen are personally compared regarding both their jewish and female identities in public and private life as well as their most intimate realm.
\end{abstract}

Keywords: Space, Pariah, Assimilation, Jewish Identity, Female Identity

\footnotetext{
${ }^{1}$ grojosilva@gmail.com
}

La autora desea agradecer al profesor Maximiliano Figueroa de la Facultad de Artes Liberales de la Universidad Adolfo Ibáñez por su entusiasta apoyo en el desarrollo de este artículo. 


\section{INTRODUCCIÓN}

El descubrimiento de una vocación puede surgir a través de las maneras más inesperadas: un libro, una experiencia o una persona especial pueden constituir en la vida de alguien un punto de inflexión del cual ya no hay retorno posible. El objetivo de este trabajo es descubrir cómo, a partir del libro escrito sobre Rahel Varnhagen (1771-1833), intuyó la pensadora Hannah Arendt los primeros conceptos de la teoría política que fue desarrollando a lo largo de su obra de madurez. Se quiere detectar en este libro los esbozos de algunos estos conceptos políticos, tales como el espacio público y privado, la natalidad, la pluralidad, la acción, y muy en especial la figura del paria o marginado, a la cual prestará mucha atención por causa de eventos históricos vividos por sí misma.

Tal como en un espejo de agua clara, los documentos sobre Varnhagen significaron una revelación para Hannah Arendt al verse reflejada en la intelectual del siglo XIX y sus circunstancias. En la transparencia del relato de las experiencias de Rahel Varnhagen en el mundo encontró Arendt una razón para reenfocar su pensamiento y su obra de una manera tal que se iría tanto acercando a la teoría política, como alejando de la filosofía tradicional.

El texto principal que examina este trabajo es Rahel Varnhagen: The life of a Jewess, el cual es leído y analizado dentro del contexto de las ideas políticas presentadas en obras posteriores de Hannah Arendt.

Este artículo se divide en dos partes. En la primera revisaremos el marco teórico que consiste en un breve examen de las identidades judía y femenina en las épocas en que vivieron Varnhagen y Arendt, así como del fenómeno de los salones literarios en la Alemania del Romanticismo. Haremos también un análisis de los conceptos políticos desarrollados por Arendt que pueden ser encontrados en el libro sobre Rahel Varnhagen.

En la segunda parte nos concentraremos en un punto muy importante que es la semejanza en las experiencias sentimentales de Rahel Varnhagen y Hannah Arendt, siguiendo con una comparación entre ambas mujeres, examinando sus similitudes y diferencias. Se finaliza con las conclusiones y un análisis del cumplimiento de los objetivos del trabajo.

El marco histórico presentado explica el entorno social y político en el cual vivió y actuó Varnhagen ya que este explica en gran medida sus acciones, pensamientos y sentimientos. Rahel tuvo una identidad como mujer y 
como judía, la cual se vio transformada posteriormente como resultado de su entrada al ámbito social mediante un salón literario, fenómeno relevante en su época del cual también hacemos una breve reseña.

El libro sobre Rahel Varnhagen fue escrito en su mayor parte entre 1932 y 1933 antes de huir Hannah Arendt de Alemania una vez que el nacionalsocialismo hubo asumido el poder. El libro trata sobre la vida de esta intelectual y de su manera de estar en el mundo que le tocó vivir: el reino de Prusia en la época del Romanticismo.

Hannah Arendt nunca pretendió escribir un análisis sobre la persona de Rahel Varnhagen, sino que su intención fue "contar la vida de Rahel de la manera que ella misma podría haberlo hecho" (Venmans 2015, 28). Arendt quiso que Rahel hablara a través de su propia voz, reescribiendo lo que el marido de esta, el prusiano Karl Varnhagen von Ense, había censurado al publicar inicialmente el Buch des Andenkens (libro de recuerdos) tras la muerte de su mujer. Dicha censura fue principalmente aplicada a los pasajes que hablaban de la condición judía de Rahel, quien nació con el apellido Levin. Arendt dedicó, por lo tanto, su obra biográfica a reconstruir esa condición e interpretar qué significaba ser una mujer judía en Prusia en la época del Romanticismo. Para este efecto, Hannah Arendt trabajó con el Buch y algunas cartas intercambiadas entre Rahel y sus cercanos que no se encontraban publicadas a la fecha de su trabajo.

Las similitudes entre Hannah y Rahel fueron inmediatamente vistas por la autora: ambas eran mujeres, alemanas y judías, y muchos de los eventos en la vida de Rahel tenían un claro paralelo en la de Hannah, tanto en relación con el ámbito público como en el privado. Estos parecidos hicieron que despertaran tanto el interés como la conexión de Hannah Arendt con la persona de Rahel Varnhagen.

Rahel Varnhagen puede ser descrita como "la judía paria del Berlín romántico cuya búsqueda infeliz de la asimilación imposible sirvió a Arendt para entenderse a sí misma en el Berlín prehitleriano" (Arendt 2005, 9). La misma Arendt reflexiona respecto a esta obra:

El problema judío estaba presente, por supuesto. Pues lo escribí con la misma idea: Quiero comprender. No eran mis problemas personales como judía los que yo discutía ahí. Pero ahora la pertenencia al judaísmo se había convertido también en mi problema, y mi propio problema era político, ipuramente político! (Arendt 2005, 29) 
Agrega Arendt al respecto: "La lucha que lleva a cabo Rahel contra los hechos, sobre todo contra el hecho de haber nacido judía, se convierte muy rápidamente en una lucha contra sí misma" (Kristeva 1999, 98). Rahel Varnhagen, tal como diría San Agustín, se había convertido en un problema para sí misma.

Para Rahel su nacimiento judío había sido más que nada una vergüenza, y durante toda su vida renegó de él hasta que finalmente lo aceptó llegada ya a la vejez. Sin embargo, a lo largo de gran parte de su vida, se sintió marginada por más de una razón: por ser judía, por ser mujer y además por carecer de fortuna y belleza. Respecto a su condición de ser una mujer carente de belleza nada podía hacer, pero el "problema" de su judaísmo y el de falta de fortuna podían ser resueltos simultáneamente a través de la asimilación social por medio de un matrimonio ventajoso. Sin belleza, sin dinero ni una vasta cultura, Rahel carecía de "las armas con las cuales pudiera comenzar la gran lucha por el reconocimiento y la existencia sociales, por una porción de felicidad, por la seguridad y una posición establecida en el mundo burgués" (Arendt 1997, 88). Sin embargo, Rahel decidió hacer algo por sí misma y, armada con su inteligencia innata, cultivó en su casa un salón literario donde se reunían intelectuales y algunos aristócratas que no participaban de la sociedad respetable: "Era una interlocutora brillante. Ella vino, habló y conquistó" (Arendt 1997, 101). Es en ese contexto que Rahel intentó desesperadamente culminar su asimilación social a través del matrimonio con un gentil preferentemente aristócrata.

Dado que el hecho que un grupo se vea o simplemente se sienta marginado de su entorno es un fenómeno intrínsecamente político, el análisis que hace Arendt de las causas y los efectos de esta marginación en Rahel y en quienes la rodearon representa su punto de entrada en el mundo de la teoría política. Se llevará por lo tanto a cabo en este trabajo una profundización en el estudio del marginado o paria, entre otros conceptos, con especial énfasis en sus formas judía y femenina.

La importancia de este análisis reside en que el estudio que hace Arendt de todos estos conceptos nunca ha perdido su validez: lo fue tanto para Varnhagen en su sociedad y época como para la misma Arendt en las suyas. Se quiere demostrar con esto que el pensamiento de Arendt nos puede arrojar luces muy clarificadoras sobre cómo podemos enfrentar los problemas que trae la actualidad y que son analizados por autores como Bauman, Onfray, Agamben y Zižek, entre otros. ${ }^{2}$

${ }^{2}$ Las traducciones de las citas escritas originalmente en idioma extranjero son de responsabilidad de la autora. 


\section{MARCO HISTÓRICO Y SOCIAL}

\section{a. La identidad femenina en los siglos XVIII y XIX}

La idea sobre la mujer y su rol en la época de Rahel Varnhagen puede ser inicialmente dilucidada a partir de algunos textos de filósofos contemporáneos como Kant, Hegel y Nietzsche. Esto es importante para entender el escenario en que Varnhagen estaba inmersa y era observada.

Kant, en su breve obra llamada Observaciones acerca del sentimiento de lo bello y lo sublime hace una clara distinción entre ambos sexos, atribuyendo "lo bello" a lo femenino y "lo sublime" a lo masculino, diferenciando además los sentimientos que estas características pueden provocar. Aunque lo noble o sublime puede ir unido con lo bello (Kant 2015, 41), el filósofo señala que las mujeres básicamente poseen:

... un sentimiento innato más intenso para todo lo que es bello, lindo y adornado ... Ellas tienen sentimientos comprensivos, cordialidad y compasión, prefieren lo bello a lo útil y ahorrarán de la abundancia en el sustento para subvenir al gasto de su brillo y su atavío. Son muy sensibles para advertir la más pequeña falta de atención y de respeto hacia ellas. En resumen, ellas tienen el fundamento principal del contraste en la naturaleza humana de las cualidades bellas con las nobles, y hasta llegan a refinar al sexo masculino (Kant 2015, 69).

Continúa Kant diciendo al respecto:

Una reflexión profunda y un tratamiento largo y continuado son nobles, pero pesados y no se corresponden bien con una persona en la que los atractivos naturales no deben mostrar otra cosa que no sea una naturaleza bella. Aprender con trabajo o cavilar con esfuerzo... hacen desaparecer los primores que son propios de su sexo, y pueden convertirse en objeto de una fría admiración a causa de su rareza, pero debilitan al mismo tiempo los encantos mediante los cuales ejercen ellas su gran poder sobre el otro sexo. Una mujer que tenga la cabeza llena de griego ... o que mantenga discusiones profundas sobre la mecánica ... únicamente puede en todo caso tener además barba (Kant 2015, 69-70). 
En definitiva, para Kant la tarea de la mujer es realzar su belleza para beneplácito del hombre, a lo cual debe agregar la expresión de una sensibilidad acorde a su naturaleza. No necesita saber mucho tampoco sino solo ser ingeniosa, ya que "el entendimiento es sublime, [y] el ingenio es bello" (Kant 2015,39 ), debiendo ser el marido su maestro (Kant 2015, 86): “... en la vida matrimonial, la pareja unida debe constituir, en cierto modo, una persona moral única, animada y regida por la inteligencia del hombre y el gusto de la mujer" (Kant 2015, 89).

Nietzsche es mucho más duro en su percepción de la mujer, indicando que el hombre debe ver a la mujer con piedad señalando que:

Hasta se quiere convertir a las mujeres en librepensadores y literatos: como si la mujer vista sin piedad no fuera para el hombre una cosa perfectamente chocante y ridícula... Se las vuelve día a día más histéricas y más incapaces para cumplir su primera y última función, echar al mundo hijos robustos (Nietzsche citado en Figueroa 2006, 347).

Incluso rebaja a la mujer de su condición humana indicando que "parece más apta para sufrir, más frágil, más sedienta de amor que ningún otro animal" (Nietzsche citado en Figueroa 2006, 347).

Por su parte, Hegel indica que "la diferencia entre el hombre y la mujer es igual a la que existe entre el animal y la planta. El animal se asemeja en carácter al hombre, y la planta a la mujer, ya que esta última evoluciona en mayor medida desplegándose tranquilamente, teniendo por principio la unidad indeterminada del sentimiento" (Hegel citado en Rogers 2000, 1). Hegel hace una clara distinción entre el ámbito público y el privado - conceptos que analizaremos más adelante -, situando a la mujer exclusivamente dentro del segundo. La casa es la sede de la vida privada y las relaciones entre quienes viven allí están basadas en el sentimiento de amor y en la piedad, razón por la cual constituye el dominio de la mujer. De esta manera ella queda excluida de la vida pública porque al estar dominada por los sentimientos no es capaz de hacer frente a la vida civil (Rogers 2000,6).

Hegel asimismo llega a aproximarse a Nietzsche en el tratamiento a las mujeres como seres diferentes e incluso inferiores a los hombres:

Hegel sugiere que las mujeres no son individuos, al menos no en la misma medida y en la misma extensión que los hombres. Son incapaces de la lucha espiritual y la separación que caracteriza la 
vida de los hombres ... Lo más significativo es el hecho de que aquellos aspectos en los que Hegel considera distintos espiritualmente a hombres y mujeres son los que definen a las mujeres como seres humanos "menores" ... Hegel no solo asigna particularidad, intuición y pasividad a las mujeres y universalidad, pensamiento conceptual y "lo poderoso y lo activo" a los hombres, sino que ve en estos últimos las características que definen a la especie como humana (Benhabib 2006, 277).

El ámbito de acción de las mujeres en el siglo XIX fuera de la casa se restringía principalmente a la enseñanza y la caridad en el caso de las de mejor fortuna. No había mujeres universitarias, pero sí existía para ellas la formación pedagógica. Una mujer debía, por lo tanto, realizarse principalmente a través del matrimonio, lo que le daba una cierta seguridad económica y social. Esto se volvía una necesidad imperativa en el caso de algunas, ya por convención o porque no sentían que tuvieran las herramientas necesarias para vivir una vida por y para sí mismas y necesitaban por lo tanto un marido que las mantuviera, protegiera y validara socialmente, sin necesariamente ser el mejor compañero en el más completo de los sentidos.

\section{b. La identidad judía en los siglos XVIII, XIX y comienzos del XX}

La misma Hannah Arendt nos relata en su libro Los orígenes del totalitarismo la evolución de la situación de los judíos en Prusia, en especial en el Berlín donde vivió Varnhagen. Dentro de un ambiente adverso hacia los judíos por ser considerados un grupo separado de la sociedad, se consiguió pervertir "todas las relaciones sociales entre los judíos y los gentiles, y ... [con lo que se logró] un efecto definido en la conducta judía" (Arendt 2006, 128). Los judíos, en el mejor de los casos, eran "tolerados, pero usualmente oprimidos y perseguidos" (Arendt 1997, 88).

Muchos judíos intentaron asimilarse a la sociedad alemana a través de su total inmersión en la cultura nacional y gentil. Sin embargo, esto - indica Arendt - les exigió convertirse en judíos excepcionales y muy diferentes a los otros integrantes de su comunidad. Un ejemplo de esto fue Moses Mendelssohn, quien logró integrarse a la sociedad alemana y llegar a ser uno de los más grandes pensadores de la Ilustración (Venmans 2015, 24). Según Arendt, esto se debió a la influencia de Herder y la búsqueda de "nuevos especímenes de la humanidad" con los que se pudiera llegar a convivir amistosamente (Arendt 2006, 131). El éxito de la obra de Lessing llamada Nathan el Sabio y sus ideas de amistad y pluralidad hizo que parte de los prusianos ilustrados se volvieran hacia los judíos buscando estos nuevos especímenes "más humanos". 
Luego de la derrota de Prusia en 1806 a manos de los ejércitos napoleónicos saltó a la discusión púbica el tema de la emancipación judía, la que arrojó como resultado el otorgamiento de derechos — civiles, pero no políticos- a los judíos. Muchos de ellos, ya integrados a la sociedad alemana, reaccionaron extremando su asimilación —es decir, alejándose más aún de los otros judíos- a través de la conversión al cristianismo o bien haciendo más notoria la diferencia con ellos, sea por riqueza o cultura y así lograr seguir siendo excepcionales (Arendt 2006, 133-134). Sin embargo, estos judíos asimilados nunca conformaron una tradición política por sí solos, sino que permanecieron apolíticos a juicio de Hannah Arendt (Venmans 2015, 25). Este hecho les permitió introducirse en las finanzas del estado y mantener relaciones privilegiadas con el poder a través de su dinero. Esto, sin embargo, los encegueció respecto de la amenaza que constituía la política antisemita a la cual siempre se vieron enfrentados (Arendt 2006, 127).

A diferencia de Rahel Varnhagen, Hannah Arendt vivió en una Alemania donde las mujeres podían vivir una vida más emancipada, donde no era extraño verlas en la universidad y se luchaba por el derecho al voto femenino (Young-Brühl 2006, 76).

Hannah Arendt creció en Königsberg (Prusia Oriental) en un ambiente de profesionales judíos acomodados. Sus padres eran socialistas y en su casa se encontraban los clásicos griegos y latinos ya que sentían afinidad con las humanidades. Aunque no eran religiosos, animaron a Hannah a asistir a la sinagoga.

Su condición de judíos de nacimiento no fue un tema relevante en su casa, tanto que Arendt se enteró de ello cuando otro niño le hizo en la calle un comentario antisemita. Su madre, muy sabiamente, le indicó cómo debía reaccionar en casos como aquél y qué debía hacer cuando el comentario viniera de un profesor o un adulto (Young-Brühl 2006, 74). A pesar de haber crecido en un ambiente judío asimilado, el antisemitismo era una constante en la sociedad alemana de la época y Arendt no se vio librada de sus manifestaciones. Relata su primer marido Günther Anders una confesión que le hizo la misma Arendt respecto de esto: "Pues a las muchachas como yo que tienen un aspecto tan acusadamente judío, incluso a las guapas, las ignoran por completo, y eso en el mejor de los casos. Incluso en el comedor de la universidad" (Anders 2013, 59).

El panorama social para los judíos no sufrió mayor cambio hasta la llegada de Hitler al poder en 1933 y la posterior persecución a la que se vieron sometidos debido al antisemitismo del régimen y sus ideas de pureza racial, desencadenándose así el mayor holocausto que haya sufrido el pueblo judío, ocasión en que su estado de aislamiento de la sociedad se vio rebajado a un nivel tal que no bastó con la exclusión y el menosprecio, sino que fue sujeto de una política sistemática de exterminio, junto con otros como los 
gitanos, eslavos, discapacitados físicos y mentales, homosexuales y opositores políticos. Este hecho marcó otra inflexión - grande y dolorosa - en la vida y pensamiento de Hannah Arendt, quien analizó brillantemente este fenómeno en su libro Los orígenes del totalitarismo, el cual ya hemos mencionado.

\title{
c. Los salones literarios en la actual Alemania de finales del siglo XVIII y el siglo XIX
}

Examinaremos brevemente el fenómeno de los salones literarios de la época del Romanticismo en lo que hoy llamamos Alemania, ya que, tal como veremos más adelante, este fue el medio que Rahel Varnhagen utilizó para encontrar su lugar en el mundo.

Los salones literarios no fueron una exclusividad alemana: también en la Francia revolucionaria hubo salones dirigidos por mujeres teniendo incluso a Robespierre como uno de sus asistentes (Godineau 2002, 32).

\begin{abstract}
Estas mujeres, a través de sus vidas y amistades, salones y contactos y, en algunos casos, a través de sus cartas, publicaciones y traducciones, no solo fueron antecesoras de los primeros pasos en la emancipación de la mujer, sino también representantes de un nuevo modelo de relaciones entre géneros, al aspirar a la igualdad, el amor libre y la reciprocidad (Benhabib 2006, 282).
\end{abstract}

Los salones literarios más conocidos en Berlín entre fines del siglo XVIII y comienzos del XIX fueron de mujeres judías, las cuales se apartaron de lo que se esperaba de ellas: una vida familiar tradicional con una religiosidad absolutamente doméstica.

Estos salones fueron además un "territorio neutro" donde podían confluir las personas más diversas: artistas, intelectuales, nobles ricos y pobres, así como también judíos de fortuna. La condición exigida para poder pertenecer a estos salones se reducía a tener una "personalidad cultivada", sin importar el origen, el sexo, ni la actividad de la persona (Arendt 2005, 80). Esta personalidad debía ir también acompañada de "singularidad de carácter, talento y expresión" (Arendt 2006, 134).

Este escenario, un espacio social de dimensiones relativamente reducidas, significó una plataforma de asimilación para algunas mujeres judías que se casaron con hombres de la nobleza. Estas mujeres tampoco eran judías tradicionales, sino hijas de familias a las que fue otorgada la mejor educación posible: idiomas, artes y lectura, sin hacer mayores distinciones entre niños y niñas (Green 2002, 265). Este círculo además apoyó una reforma 
religiosa que devino en formas menos ortodoxas del culto judío y más aproximadas al laicismo. Todo esto hizo que estas mujeres se alejaran del judaísmo tradicional abriéndose a otras formas de vida (Green 2002, 265).

Dice Hannah Arendt al respecto:

Esta sociedad berlinesa [el llamado "salón berlinés"] tuvo una génesis breve y una duración corta. Surgió del "Berlín académico" de la Ilustración, lo que explica su neutralidad social ... Con esta neutralidad social del salón se corresponde la indeterminación social de la judería berlinesa, que estaba en un proceso asombrosamente rápido de asimilación. Los judíos no tenían que empezar por desligarse de todos sus posibles vínculos sociales, pues desde un principio estaban fuera del espacio social sin más. Y si los hombres judíos aún mantenían algunos vínculos a través de su profesión, las mujeres judías - si es que estaban emancipadas - se encontraban libres de todas las convenciones en una medida que hoy se hace difícil de imaginar. Estas casas judías se convirtieron en el punto de encuentro del mundo intelectual sin que sus propietarios pudiesen sentirse propiamente comprometidos ni honrados por ello (Arendt 2005, 77-78).

El más representativo de estos salones y de la sociedad genuinamente mezclada que se dio gracias a ellas en Alemania, fue el de Rahel Varnhagen. Su inteligencia ... combinada con un interés absorbente por la gente y una naturaleza verdaderamente apasionada, hizo de ella la más brillante e interesantes de estas mujeres judías. Las modestas pero famosas soirées en el desván de Rahel reunió a aristócratas "iluminados", intelectuales de clase media y actores - esto es, todos quienes, como los judíos, no pertenecían a la sociedad respetable. Por lo tanto, el salón de Rahel ... fue establecido en los límites de la sociedad y ... no compartía ninguna de sus convenciones o prejuicios (Arendt 1997, 4).

Dado que estos salones fueron relevantes en su época, y además como resultado de este interés por cultivarse, las mujeres comenzaron a hacer literatura por sí mismas. Esto evidentemente produjo reacciones poco amables en muchos - como hemos visto anteriormente con Nietzsche - aunque otros estuvieron de acuerdo e incluso lo fomentaron. Con una calidad usualmente variable hubo novelistas, poetisas y otras que cultivaron el género epistolar. Sin embargo, esto nunca fue valorado de la misma manera que la 
literatura masculina, sino simplemente calificado de Damenliteratur. Muchas mujeres incluso escribían a escondidas como si esto fuera una falta gravísima: "Mi marido ha siempre ignorado que yo escriba poesía y nunca le he hablado de esto" (Ackermann citada en Duby y Perrot 2002, 175).

La calificación peyorativa de "literatura de señoras" y las suspicacias que despertaban en la sociedad respetable estas aventuras literarias de las mujeres se prolongaron por varias décadas y pueden verse claramente reflejadas en la anécdota que cuenta la escritora Louise Aston (citada en HoockDemarle 2002, 198) respecto de un diálogo que sostuvo con el ministro jefe de la policía prusiana:

ASTON: "En el interés de mi carrera literaria, me es deseable una estadía en Berlín donde siempre encuentro nuevas inspiraciones".

MINISTRO: "Ciertamente no es de nuestro interés que Ud. difunda aquí sus futuras obras, las cuales serán sin duda alguna tan libres como sus propósitos".

ASTON: "Entonces, Su Excelencia, si el Estado prusiano comienza a sentir miedo de una mujer es porque ha caído demasiado bajo".

Los salones berlineses, tal como fueron conocidos en un principio, se terminaron en 1806 producto de la invasión napoleónica y aquellos que permanecieron vigentes tomaron un carácter aristocrático y exclusivo por el que los judíos fueron esta vez descartados junto con las mujeres (como un rechazo tácito a los salones judíos, según Arendt), los franceses y aquellos que no gustaban de las artes en general (Arendt 1997, 177). Se lamenta Varnhagen en una carta de 1808 a una amiga: “QQué ha sido de nuestro tiempo? Cuando estábamos todos unidos... Hundido como un navío, que se lleva consigo los más bellos bienes de la vida, sus más bellos gozos" (Arendt 2005, 83).

\section{ANÁLISIS POLÍTICO DEL LIBRO SOBRE RAHEL VARNHAGEN}

Hannah Arendt plantea la política, a juicio de Laura Boella, como "una dimensión existencial, que atraviesa toda forma de actividad y de experiencia, que no es técnica de gobierno sino arte y placer de estar juntos, de intercambiar ideas y palabras" (Boella 2010, 17).

El "estar juntos" de Boella significa que el ser humano no debiera estar aislado. Una persona sola no hace política, puede reflexionar mucho pero su pensamiento es estéril si no lo comparte con al menos otro, de modo que ese intercambio signifique crecimiento para ambos con "arte y placer": "Por mucho que nos afecten las cosas del mundo, por muy profundamente que nos 
estimulen, solo se tornan humanas para nosotros cuando podemos discutirlas con nuestros semejantes" (Arendt 2001, 35).

El aislamiento de una persona que se retira del mundo, por la causa que sea, puede ser bueno para ella ya que puede recogerse en "su libertad de pensamiento", pero no lo es para la sociedad, la cual "sufre una pérdida casi demostrable; lo que se pierde es este estar-entre específico y a menudo insustituible que debería haberse formado entre este individuo y sus semejantes" (Arendt 2001, 14-15).

La dimensión existencial exige además un aquí, un ahora y una relación con ambos: no puede tampoco hacerse política en base a conceptos etéreos totalmente desconectados de su razón de ser que es la convivencia humana. La política es una experiencia que abarca muchas dimensiones tanto temporales como espaciales y emocionales, que va de lo personal a lo colectivo, de lo privado a lo público, del nacimiento a la muerte, del cuerpo a la mente y de los sentimientos más puros a la pasión más ciega.

La intención de este análisis es demostrar que este libro sobre la vida de Rahel constituye un "verdadero laboratorio del pensamiento político de Arendt quien forja sus futuros conceptos a partir del contacto con esta persona en particular" (Kristeva 1999, 88).

Hannah Arendt no hace un perfil psicológico de Rahel Varnhagen, sino que este tipo de estudio es "minimizado en beneficio del ensayo político: [...y de esta manera Arendt] comienza su actividad de teórica política por fuera de las normas" (Kristeva 1999, 90). Arendt indica claramente en la introducción de su libro que - como ya hemos mencionado - su intención es contar la historia de Rahel Varnhagen tal como ella hubiera querido hacerlo, respecto de sus pensamientos, sus sentimientos y su posición ante el destino: “¿Qué hago? Nada, dejo que la vida llueva sobre mí" (Arendt 1997, 81). Esto se debe a la ya mencionada censura aplicada en el Buch des Andenkens a todas las referencias inconvenientes de ser publicadas, en un intento claro de proyectar a la posteridad una imagen "respetable" de ella. La eliminación de estos pasajes y nombres de algunas personas se debe al proceso de asimilación social de Rahel que tenía como finalidad encontrar un lugar en la sociedad prusiana donde pudiera sentirse reconocida y valorada.

Tal como hemos visto con anterioridad, los judíos en el reino de Prusia de esa época no contaban con los mismos derechos que el resto de la población. Si sumamos, además, la imagen rebajada de la mujer en comparación con el hombre vemos que una mujer judía podía considerarse una paria absoluta en la sociedad de su época. Precisamente ése era el sentimiento de Rahel: la desesperación por no ser considerada como una persona igual a los demás en derechos y deberes: 
Le pareció que le habían robado, tanto la sociedad como el estado en una secreta alianza, a todos los judíos los derechos civiles y la igualdad social ... no habían recibido los más mínimos derechos que sí tenían "la campesina y la mendiga". Rahel había luchado por esta "existencia natural" robada sin poder descansar (Arendt 1997, 254-255).

Rahel sentía vergüenza de ser judía y de ser considerada socialmente inferior a "la campesina y la mendiga": "No olvido esta vergüenza por un solo segundo. Lo bebo en el agua, en el vino, del aire, cada vez que respiro" (Arendt 1997, 175).

Pasaremos a continuación a examinar los principales conceptos políticos desarrollados por Hannah Arendt tal como fueron presentados en su libro sobre Rahel Varnhagen.

\section{a. Amor por el mundo}

Uno de los grandes conceptos políticos desarrollados por Hannah Arendt es el amor o deseo por el mundo (amor mundi). Este concepto ya lo había analizado en su tesis de doctorado El concepto de amor según San Agustín dirigida por Karl Jaspers en Heidelberg y lo volvió a trabajar en su libro $L a$ condición humana.

El placer de estar con otros miembros de este mundo, como dice Boella, puede ser descrito como "la conciencia intensificada de la realidad, [que] brota del apasionado abrirse al mundo y al amor por él" (Arendt 2001, 16). Peter Venmans asimismo describe con mucha precisión este concepto de amor por el mundo presente en Hannah Arendt:

Quizás, después de todo, su mayor descubrimiento haya sido que la dignidad humana no consiste en el mero cuidado del interior de cada uno, sino que tiene que ver también con la posición que alguien adopta en el mundo, entre terceros. Solo en el mundo, en contacto con otros, en esencia diferentes unos de otros, pero desde el punto de vista político, personas completamente iguales, una persona se vuelve "alguien", puede adquirir la dignidad que eleva la vida por sobre la pura satisfacción de las necesidades biológicas. De lo que un hombre es capaz lo determinan sus actos y palabras: actividades que presuponen y crean a la vez un espacio público (Venmans 2015, 13). 
Precisamente esa dignidad fue lo que buscó Rahel con tanto afán a través de su intento de asimilación en un mundo que le estaba negado por nacimiento: “... me doy cuenta de que soy nadie. Ni hija, ni hermana, ni amante, ni esposa, ni siquiera una ciudadana" (Arendt 1997, 11). Al buscar un lugar en el mundo ella esperaba ser reconocida y llegar a ser alguien en vez de nadie. Agrega Arendt: "Ella necesitaba la experiencia de los otros para complementar la suya propia... Mientras más personas la comprendieran, más real podía ella volverse" (Arendt 1997, 98).

\section{b. Espacio público}

Hannah Arendt desarrolla también en La condición humana los conceptos de espacio público y espacio privado, a los que agrega rozando en forma casi tangencial la intimidad. Estos tres elementos participan, en distinto grado, del llamado "mundo común" que compartimos con los demás y donde no podemos actuar sin tomar en cuenta sus opiniones. Respecto del mundo común [lo que se entiende por comunidad] indica Arendt:

... la realidad de la esfera pública radica en la simultánea presencia de innumerables perspectivas y aspectos en los que se presenta el mundo común ... Pues si bien el mundo común es el lugar de reunión de todos, quienes están presentes ocupan diferentes posiciones en él ... [El] Ser visto y oído por otros deriva su significado del hecho que todos ven y oyen desde una posición diferente. Este es el significado de la vida pública ... Solo donde las cosas pueden verse por muchos en una variedad de aspectos y sin cambiar su identidad, de manera que quienes se agrupan a su alrededor sepan que ven lo mismo en total diversidad, solo allí aparece auténtica y verdaderamente la realidad mundana (Arendt 2016, 66) ... El fin del mundo común ha llegado cuando se ve solo bajo un aspecto y se le permite presentarse únicamente bajo una perspectiva (Arendt 2016, 67).

El espacio público para Rahel Varnhagen fue entonces:

El salón judío, y con mayor razón el de Rahel, se construye como un espacio social exterior [un espacio público], distante de las convenciones... Una ilusión con la cual Rahel se emborracha, creyendo que sus invitados la validan socialmente cuando sin embargo ellos permanecen profundamente indiferentes (Kristeva 1999, 99). 


\section{c. Espacio privado}

Así como este mundo común representa la esfera pública, el mundo privado (o esfera privada, que coexiste con la pública) constituye el espacio donde se está:

... privado de la realidad que proviene de ser visto y oído por los demás, estar privado de una objetiva relación con los otros que proviene de hallarse relacionado y separado de ellos a través del intermediario de un mundo común de cosas, estar privado de realizar algo más permanente que la propia vida. La privación de lo privado radica en la ausencia de los demás...(Arendt 2016, 67).

La llamada esfera privada corresponde generalmente a la casa, donde se recibe a los amigos más íntimos, y donde está la familia. Este es el lugar donde se lleva a cabo las funciones del cuerpo: dormir, comer, bañarse o recuperarse de una enfermedad, entre otros.

Por último, tenemos un terreno mucho más personal, que es el de la intimidad, de la cual Arendt define tres componentes: las pasiones del corazón, los pensamientos de la mente y "las delicias de los sentidos" (Arendt 2016, 59).

\section{d. El reino de la intimidad}

Nos vamos a detener en lo que llamaremos "el reino de la intimidad" porque es el origen de todo lo que va a la esfera privada y que puede luego salir a la esfera pública, y porque es de vital importancia para la lectura que hace Hannah Arendt de la vida de Rahel Varnhagen y al paralelo que podemos hacer entre ambas.

En el reino de la intimidad, donde la persona está sola consigo misma y es por lo tanto la soberana absoluta, tanto las pasiones del corazón como los pensamientos de la mente se alimentan de lo que los sentidos les entregan. Entre los tres arman un tejido que sostiene un conjunto de ideas, creencias, sentimientos y recuerdos, lo que conforma una sola gran Verdad compuesta a su vez por muchas verdades particulares, unas conocidas y otras desconocidas incluso para la misma persona. Esta Verdad puede quedar guardada en el reino de la intimidad (pudiendo ser brevemente desvelada a otro) o puede salir a la esfera privada e incluso a la pública en forma parcial o total. Estas dos esferas contienen otros seres humanos que rodean a la persona en distinto grado de relación. Lo que cada uno expresa de sí mismo en estos ámbitos permite a los demás intuir cómo es realmente la persona, 
tal como si el reino de la intimidad fuera un faro y la Verdad compartida fuera la luz que este proyecta.

Escribe Rahel desde su intimidad: "Las desgracias que puedan venir del Cielo las puedo soportar con toda la tranquilidad del alma. Pero cuando las heridas han sido infringidas por las personas, mi alma pierde toda su compostura y no lo puedo soportar ... no puede nadie quitarme las demandas que tengo sobre y de los demás" (Arendt 1997, 254). Rahel Varnhagen como hemos señalado anteriormente - estaba avergonzada de su "nacimiento infame" y le tomó una vida completa el perdón y la reconciliación con su identidad judía. Mientras experimentó esa gran inferioridad sintió que debía "evitar todo aquello que fuera una confirmación, no debía actuar, ni amar ni verse incluida en el mundo" (Arendt 1997, 89) Esto significa que debía estar fuera de toda esfera pública y circunscribirse a su reino de intimidad o mantenerse en la esfera privada sin jamás traspasarla. Lo que ella está reclamando desde su corazón es su justa admisión a la esfera pública, donde tiene todo el derecho de participar tal como entendemos en el concepto de "mundo" planteado por Arendt.

Rahel, a través de la extensa correspondencia que tuvo con sus amigos en el contexto de la esfera privada, abrió parte de su reino de la intimidad sin pensarlo demasiado. Rahel no sentía pudor alguno respecto de sus cartas, según Arendt debido a un exceso de candidez:

... ella quería que sus cartas fueras citadas, mostradas, admiradas, leídas y releídas (Arendt 1997, 11). Sus cartas debían ser testigos del momento en que fueron escritas porque ellas le daban un sentido de identidad... "pero si no es posible verme de tal manera, prefiero ser cualquiera antes que se nadie" (Arendt 1997, 12).

En un momento en que Rahel no soporta sentirse excluida del ámbito público ni su vergüenza por ser judía decide huir a París. En París no tiene un pasado ni un presente desgraciado y puede ser inocente de nuevo: "La inocencia existe mientras se desconozca la infelicidad" (Arendt 1997, 137). Fuera de su espacio cotidiano Rahel puede, en su reino de la intimidad, “... borrarse, carecer de nombre y de recuerdos, y así experimentar, sentir lo que todavía pueda provocar alegría” (Arendt citada en Kristeva 1999, 100).

Arendt describe la contradicción que ya podemos percibir en el comportamiento de Rahel, una dicotomía entre el querer estar y no estar en el mundo: a pesar de recibir en su casa y ser una brillante conversadora ("Nunca se está realmente con una persona salvo cuando se está a solas con ella"), mantiene una cierta distancia de la gente. La búsqueda por la felicidad se transformó para Rahel en una "pasión por la verdad ... sí deseaba 
encontrarse con ellos [otros seres humanos] en el dominio de la verdad" (Arendt 1997, 95). Sin embargo, ella seguía manteniendo su distancia de los demás: "Qué feliz es quien ama sus amigos y puede vivir tranquilamente sin ellos" (Arendt 1997, 95). Rahel por decisión propia no salía de su interior y lo que mostraba en las esferas privada y pública era solo una parte de lo que había en su reino de la intimidad. Así como quería que todos supieran de su existencia y los fascinaba con su personalidad, ella asimismo "permanecía impenetrable" (Arendt 1997, 135), consiguiendo al final que las personas se retiraran de ella muy a su pesar, ya que con esa actitud quería llamar la atención, hacerse más visible y "tangible". Respecto de esta reacción de los demás Arendt indica que se basaba solo en opiniones y no en la verdad sobre Rahel Varnhagen: "El mundo estaba lleno de opiniones y la verdad no se volvía visible solo porque alguien lo dijera en voz alta en este mundo de apreciaciones. ¿Quién iba a ser capaz de distinguir entre verdad y opinión?” La diferencia entre estos dos conceptos la analiza Arendt posteriormente en dos obras: Filosofía y política y en Hombres en tiempos de oscuridad, específicamente en los capítulos sobre Lessing y Jaspers (Arendt 2001, 13-41 y 79102).

\section{e. Tradición, historia y narración}

Rahel tuvo un verdadero amigo en Alexander von der Marwitz, un aristócrata disconforme con su posición social y con la "gente sin una debida comprensión de las relaciones humanas", haciendo referencia a los de su clase. Muy similar a su amiga, tenía sin embargo aquello de lo que ella carecía: fortuna, rango y una posición social más que aceptable. Desde ambos extremos eran dos seres muy parecidos que compartían su disconformidad con el mundo que les tocó vivir. Marwitz había confiado a Rahel que lo que deseaba era "entender todo lo que sea humano e histórico, y trabajar comprensivamente en esto" (Arendt 1997, 206). Para Marwitz el mundo era de una vulgaridad insoportable. Ella, a partir de su propia experiencia, lo ayudó a encontrar lo bueno que este podía entregarle: "Vive, ama, estudia, sé diligente, cásate si aparece la oportunidad, haz que cada trivialidad tenga un sentido y cobre vida; ése es el camino probado y verdadero, y nadie podrá impedírtelo" (Arendt 1997, 207). El valor de la amistad de Marwitz, además de haber sido este el primero en verla como un ser humano, estuvo en haber mostrado a Rahel la futilidad del mundo al cual ella tan ansiosamente quería pertenecer, ese mundo que le mostró hostilidad por ser judía y que por lo tanto nunca le otorgó "la más elemental, más importante y más mínima concesión: igualdad de derechos humanos" (Arendt 1997, 209). Agrega Arendt al respecto:

A través de su legítimo descontento este noble creyente en la historia enseñó a la judía ilustrada que la realidad no era solamente 
lo que le sucedía a cualquiera y que la sociedad a la que ella no pertenecía y tanto disgustaba a él reconocía otro tipo de realidad, una que es heredada, de tradición y que es confirmada una y otra vez a través de sucesivas generaciones. Él le enseñó que había líneas que unían lo conocido a dominios progresivamente desconocidos, desde lo cercano a lo lejano y desde el presente al pasado; líneas que se convertían en hilos a medida que se alejaban, que se volvían más y más finos, así como más y más invisibles. Solo a través de estos lazos, le hizo ver, podía aprehenderse la realidad histórica (Arendt 1997, 209).

Así como Rahel recibió de Marwitz el regalo de la comprensión de la tradición y la historia, así como también la certeza de que no todo era maravilloso en la sociedad a la que quería asimilarse, él fue retribuido en gran medida al serle enseñado el sentido común que le podía ayudar a enfrentar su propia incomodidad.

Hannah Arendt habla en la cita anterior de la importancia de la tradición y la historia en tanto ayudan a entender el presente. Arendt retomó más tarde el tema de la tradición y la historia, en su libro Entre el pasado y el futuro, y en uno de sus más famosos ensayos llamado La tradición oculta.

Para Arendt la tradición, especialmente la memoria de un pueblo, es de suma importancia, y no debe ser despreciada, ya que permite comprender los procesos que este mismo puede estar viviendo: “... no podemos tirar sin más el pasado por la borda, como si este fuese irrelevante. El diálogo con los muertos no debe extinguirse, pues tienen aún mucho que decirnos" (Venmans 2015, 252). La tradición y la historia deben ser transmitidas a través de la narración, cualquiera sea la forma que esta pueda tomar: "Tenemos la necesidad de recordar los sucesos significativos de nuestras vidas narrándolos a nosotros mismos y a otras personas" (Arendt 2001, 32).

Por otro lado, Arendt rescata el concepto de igualdad en los derechos humanos en su libro $\mathrm{El}$ origen del totalitarismo, donde plantea que todos tenemos "derecho a tener derechos" (Arendt 2006, 247), y lo relaciona con la prerrogativa de tener un lugar donde vivir y a pertenecer a un pueblo, lo que ella llama una "comunidad organizada", con una historia y una tradición compartida por todos.

\section{f. Sentido común y comprensión}

Años más tarde Rahel se casó con Karl Varnhagen, quien tenía una gran capacidad de razonar y comprender. Él ayudó mucho a Rahel a entender lo que le había estado sucediendo a lo largo de su vida y a encontrar finalmente la paz que ella tanto buscaba: 
Él removió de su vida presente, no solo de su pasado, todos los secretos, todas las oscuridades, todo lo encubierto. Ante él, quien era su constante amigo, todas las ambigüedades aparecían interpretables y consistentes ya que él conocía y comprendía la totalidad... El hecho que él diera su aprobación clara, consciente y entusiasta a todo lo relacionado con ella confirió a dicha totalidad una brillante transparencia. "Tú lo sabes todo. Eso, eso, Varnhagen, es mi gozo y mi amor por ti” (Arendt 1997, 203).

El sentido común y la comprensión son dos de los conceptos más importantes de la teoría política de Hannah Arendt, cuyo trabajo se basa en su ansia por comprender todo lo que la rodea. Arendt define el concepto de sentido común como un sano entendimiento en comunidad, una comprensión total entre los hombres:

El que se deja guiar por el sensus communis, tal y como lo entiende Arendt, es capaz de librarse de sus intereses y pasiones personales. El que lo logra, puede convertirse en "alguien": el sujeto solo surge, según Arendt, en el contacto humano (Venmans 2015, 185).

La comprensión es la racionalidad que toma en cuenta a los demás, pero que sin embargo conserva al mismo tiempo su independencia como un aspecto humano. La racionalidad nos asegura que la persona no está completamente a merced de fuerzas externas ni de su propia falibilidad (Arendt 1997, 201).

El deseo de comprensión en Hannah Arendt es vital: sin poder entender no es posible construir una teoría política: "Es una actividad sin fin, en constante cambio y variación, a través de la cual aceptamos la realidad y nos reconciliamos con ella, es decir, tratamos de estar en casa en el mundo" (Arendt 2005, 371). Asimismo, sin comprensión no es posible que los seres humanos hagan política como ella lo plantea, con reflexión, diálogo y sentido común.

La misma Hannah Arendt señala muchos años más tarde: "No, yo quiero comprender. Y si otros comprenden en el mismo sentido en el que yo he comprendido, ello me produce una satisfacción personal, como un sentimiento de estar en casa" (Arendt 2005, 19). Para ella no era importante la influencia que pudiera tener en los demás a través de su teoría política, sino precisamente su propio proceso de comprensión y el desarrollo del pensamiento en sí mismo. 
El conocimiento y la comprensión no son lo mismo, aunque haya alguna relación entre ellos. Para que haya comprensión debe haber primeramente conocimiento y este último no tiene sentido sin la comprensión, sino que son solo palabras vacías: "Debemos a Kant la distinción entre pensar y conocer, entre la razón, el ansia de pensar y de comprender, y el intelecto, el cual desea y es capaz de conocimiento cierto y verificable" (Arendt 1995, 114).

\section{g. El concepto de acción}

Hemos dicho anteriormente que Rahel se veía limitada no solo respecto a poder encontrar su lugar en el mundo, sino también a la capacidad de actuar en él. El concepto de acción es también muy importante para Hannah Arendt y lo trató en su libro La condición humana a través de la noción de vita activa. Arendt define la acción como:

... [la] única actividad que se da entre los hombres sin la mediación de cosas o materia, [que] corresponde a la condición humana de la pluralidad, al hecho de que los hombres ... vivan en la Tierra y habiten en el mundo. Mientras que todos los aspectos de la condición humana están de algún modo relacionados con la política, esta pluralidad es específicamente la condición de toda vida política ... La pluralidad es la condición de la acción humana debido a que todos somos lo mismo, es decir, humanos, y por tanto nadie es igual a cualquier otro que haya vivido, viva o vivirá (Arendt 2016, 22).

Hannah Arendt había tratado este concepto con anterioridad en su tesis doctoral, la cual hemos mencionado con anterioridad, llamada El concepto de amor en San Agustín. El concepto de vita activa es presentado por San Agustín como vita negotiosa o actuosa, en el sentido de "vida dedicada a los asuntos público-políticos" (Arendt 2016, 26). Por eso la vida activa debe darse en un contexto de hombres que viven juntos, es decir, en una comunidad humana. Y ese contexto de comunidad donde se da la acción es lo que a su vez Arendt llamó "esfera pública" donde cada persona sale de lo estrictamente privado para interactuar con otros que son sus iguales.

Agrega además Arendt respecto del pensamiento: "La principal distinción, políticamente hablando, entre pensamiento y acción radica en que estamos solos con nuestro propio yo y con el yo del otro mientras pienso, en tanto que estoy en compañía de muchos otros en el momento que empiezo a actuar" (Arendt citada en Bauman 2016, 90). 


\section{h. Natalidad y pluralidad}

Rahel quería salir a la sociedad del lugar donde vivía, así como también experimentar un nuevo nacimiento que no fuera vergonzoso y que le permitiera desenvolverse y participar naturalmente en el mundo que tanto deseaba. Con su nuevo nacimiento Rahel podría lograr encontrar un lugar en el mundo de acuerdo con lo que Hannah Arendt explicó más adelante en La condición humana respecto de la importancia de la natalidad: Así como la muerte significa separarse de la comunidad humana, el nacimiento de un niño significa la llegada de un nuevo miembro de esta, alguien que tendrá un espacio donde podrá eventualmente participar. El niño que nace tendrá la capacidad de "empezar algo nuevo [un comienzo], es decir, de actuar" (Arendt 2016, 23).

Este concepto de natalidad, intrínsecamente unido al de comienzo, es central en la teoría política de Hannah Arendt, y va unido a otros dos conceptos que son el de pluralidad y el de acción. Complementando la cita anterior sobre la acción (Arendt 2016, 22), podemos agregar:

La acción ... no tiene sentido en soledad. Solo se desarrolla ante la presencia de otros [que han nacido también en la Tierra], esto es, requiere un espacio público en el que pueda desarrollarse (Sánchez 2003, 138-139).

... es la acción la que mantiene la más estrecha relación con la natalidad ya que, con cada ser humano, con cada nacimiento, comienza un nuevo curso de acción, una nueva iniciativa en el mundo. Por ello la acción implica un "segundo nacimiento", un nuevo comienzo en la esfera pública (Sánchez 2003, 139).

Es así como Rahel intentó salir del estado de muerte o ausencia del mundo para ingresar a él por medio de un segundo nacimiento, el cual llevó a cabo a través de la acción de presentarse en el espacio público que fue el salón literario.

\section{i. Parias y advenedizos}

Para analizar a Rahel Varnhagen y el problema de su judaísmo, Hannah Arendt tomó de Bernard Lazare (1865-1903) los conceptos de paria y advenedizo, pudiendo ser calificado el primero como consciente o inconsciente (quien sabe y quien no sabe que es paria, respectivamente). El advenedizo 
es quien decide renegar de la condición que lo hace un paria, dejando atrás $\mathrm{u}$ ocultando su identidad y tradiciones.

Explica Lazare que "[El paria consciente es] portador de una tradición oculta, alimentada por el orgullo y la grandeza de los perseguidos" (Lazare citado en Kristeva 1999, 95). Asimismo "debe... [este] rechazar al advenedizo como un signo de decadencia que nos envenena, y por medio de la rebelión, defender a los oprimidos y a su nación" (Lazare citado en Kristeva 1999, 95). La utilización por parte de Arendt de estos conceptos en el análisis de la vida de Rahel Varnhagen constituye el factor más gravitante para considerar su obra un estudio político más que una biografía.

Hannah Arendt se autodefinió orgullosamente como una paria consciente, no solo por ser una judía en Alemania, sino también desde el punto de vista de su pensamiento, el cual mantuvo estrictamente independiente: "nunca quiso abandonar esa condición para convertirse en una parvenue [advenediza], para reconciliarse definitivamente con un mundo que nunca había sentido como propio" (Arendt 2016, VII). La misma Arendt señala que en su historia "no habría tenido sentido unirse a quienes se habían asimilado; yo, además nunca tuve nada que ver con ellos" (Arendt 2005, 28-29).

En su obra Hombres en tiempos de oscuridad señala Arendt respecto de los pueblos parias y la fraternidad especial que se da dentro de ellos:

Este tipo de humanidad se vuelve inevitable cuando las épocas se tornan tan oscuras para ciertos grupos de personas que el hecho de apartarse del mundo ya no depende de ellos, de su discernimiento o elección ... Este tipo de humanidad [fraternal] es el gran privilegio de los pueblos paria ... Sin embargo, este privilegio tiene un precio muy alto; a menudo va acompañado de una pérdida tan radical del mundo, [... que] podemos hablar de una verdadera carencia de mundo (Arendt 2001, 23).

En una sociedad basada en el privilegio, el orgullo del nacimiento y la arrogancia del título, el paria instintivamente descubre la dignidad humana en general mucho antes que la Razón la haya convertido en la base de su moral (Arendt 1997, 248).

Respecto del pueblo judío como paria, indica la misma Arendt: "El pueblo judío sufrió la pérdida del mundo con la dispersión, e, igual que en todos los pueblos paria, ello generó una calidez humana entre sus miembros enteramente peculiar" (Arendt 2005, 34). En la sociedad occidental el pueblo judío siempre ha sido el paria por excelencia. En el caso de los judíos, y como 
hemos visto en la persona de Rahel Varnhagen, "perder el mundo" se refiere a perder la oportunidad de entrar en la esfera pública en el país que los ha acogido sin darles una identidad ciudadana completa, como fue el caso del reino de Prusia.

Muchos parias llevan a cabo un ascenso a través de una carrera como advenedizos, y deben hacerlo a través de la mentira, lo que es más "generalizado que la simple hipocresía". La posición de los advenedizos sin embargo nunca fue segura, estando estos hasta cierto punto autoengañados, ya que un judío asimilado e incluso convertido al cristianismo no deja de ser judío:

La historia ha demostrado que el éxito de los judíos advenedizos era superficial y traicionero. Los ánimos podían cambiar y entonces uno se quedaba sin nada... El comportamiento advenedizo estaba bastante difundido entre los judíos que aspiraban activamente a la asimilación. De esta manera, no solo se desolidarizaban de los suyos, sino que sus aspiraciones se basaban, según Arendt, en la negación de quiénes eran realmente (Venmans 2015, 31).

Los judíos que intentaron asimilarse no lo hicieron como una comunidad, sino que fue a través de un proceso individual, tal como lo intentó repetidamente Rahel Varnhagen. Intentarlo en grupo habría sido claramente una acción política que habría llamado la atención y quizás provocado alguna reacción también política de la sociedad o bien de las autoridades. La acción individual era más disimulada, razón por la cual podía tener un mayor éxito.

La asimilación social de los judíos era facilitada por las habilidades sociales de sus mujeres: "En esos días, las mujeres eran efectivamente los agentes de asimilación social ... Entre los judíos ... las mujeres son ... cien por ciento mejores que los hombres" (Gentz citado en Arendt 1997, 108).

El proceso de asimilación de Rahel Varnhagen tiene como punto de partida la negación de su nacimiento judío y desemboca en la conversión religiosa al cristianismo, junto con un cambio completo de nombre y la búsqueda de un marido perteneciente a la sociedad de la cual Rahel quiere formar parte. Indica Arendt al respecto: "No he tratado más que un aspecto del problema de la asimilación: la manera cómo el proceso de asimilación a la vida espiritual y mundana del medio ambiente ha impactado sobre una vida humana, y ha podido además convertirse en el destino de una persona" (Arendt citada en Kristeva 1999, 93).

Rahel era una paria consciente que quería por todos los medios convertirse en una advenediza, ya que no conocía en todo el mundo "tierra natal alguna donde pudiera buscar un refugio contra el destino... No tiene nada 
más que decir la verdad, que entregar un testimonio, que acumular la opulenta cosecha de la desesperación" (Arendt citada en Kristeva 1999, 99). Rahel necesitaba huir del judaísmo y no había para ella otra forma de asimilarse: "El judío debe ser extirpado de nosotros, esta es la verdad sagrada, y debe ser llevado a cabo incluso si la vida fuera arrancada en el proceso" (Arendt 1997, 175).

Dentro de los múltiples intentos que hizo Rahel Varnhagen por asimilarse a la sociedad berlinesa, siempre bajo la deseable figura de una unión con un gentil, uno tuvo éxito cuando contrajo matrimonio con el prusiano Karl Varnhagen. Sin muchas más alternativas, decidió unirse a él para poder escalar juntos en la sociedad. Su marido era inicialmente joven, pobre, no tenía rango ni nombre (Arendt 1997, 223). Karl Varnhagen se volvió un advenedizo tal como su mujer, y lo hizo a través de ella llevando el arte del escalamiento social "a la perfección", logrando incluso, junto con empleos sucesivamente mejor remunerados, rescatar un título de nobleza que sumó a su apellido el de von Ense. Reflexiona Arendt al respecto:

\begin{abstract}
Como todos los advenedizos, ella nunca esperó un cambio radical en las condiciones generales ... sino una mejora en las personales ... La sobreestimación del advenedizo sobre sí mismo, que a veces parece ser exagerado, viene del tremendo esfuerzo y de las tensiones en [que coloca] todas sus fuerzas y talentos para poder subir unos pocos escalones en la escala social. El más pequeño éxito, ganado con tanto trabajo, lo llena con la ilusión de que todo es posible, y el más mínimo fracaso lo arroja también en lo más profundo de la nulidad social; esto lo lleva a la más lamentable adoración al éxito (Arendt 1997, 239).
\end{abstract}

De acuerdo con lo indicado por Arendt, Rahel efectivamente tuvo una mejora en sus condiciones personales: "Ahora tengo que comportarme ante la gente como si fuera nada más que mi propio marido; antes yo era nada: eso al menos es un gran cambio" (Arendt 1997, 245).

Para culminar acertadamente la asimilación era necesaria además una seguridad económica, ya que "el precio de la pobreza era la soledad tal como se le había mostrado con cruel claridad" (Arendt 1997, 220-221). La fortuna era requerida como alternativa al rango. Los judíos no tenían relación con la burguesía sino directamente con la nobleza, lo cual explica el "breve lapso en que entraron en ella, cuando las casas de la burguesía permanecieron cerradas para ellos" (Arendt 1997, 221).

Sin embargo, los comentarios venenosos sobre los advenedizos nunca faltaron, como este de Humboldt: "He escuchado que [Karl] Varnhagen se 
ha casado con la pequeña Levy [sic]. Así que ahora ella podrá ser la mujer de un embajador y ser tratada como 'Su Excelencia'. No hay nada que los judíos no puedan lograr" (Arendt 1997, 238).

Ante la sociedad respetable ella siguió siendo una advenediza y sufrió muchos desaires por eso, a pesar de haber finalmente adquirido dinero, nombre, rango y estatus de mujer casada. Pagó por ello el precio de la libertad que tiene el paria de poder disfrutar las cosas simples de la vida sin tener que fingir ser alguien diferente.

Como parte de su proceso de asimilación nacieron en Rahel sentimientos patrióticos, los cuales tuvieron la oportunidad de verse encauzados en una acción específica y por una vez, estando fuera de Alemania antes de su matrimonio, pudo sentirse una mujer plenamente alemana atendiendo soldados heridos en la guerra contra las tropas napoleónicas. Fue en esa ocasión cuando pudo gozar de un prestigio que en su país no podía obtener, ya que en el extranjero las diferencias sociales se veían borradas y ella dejaba de ser una paria:

En este lugar fuera de mi país no puedo recibir gente en mi propia casa, no me puedo comunicar, pero al menos tengo el título y rango de extranjera. Y naturalmente el resultado es que soy aceptada, y toda situación de estar fuera de lugar, todo el dolor del pasado, se han desvanecido" (Arendt 1997, 233).

Rahel nunca fue, para Hannah Arendt, totalmente paria ni completamente advenediza, sino que se situó en un punto medio (Arendt y Jaspers $1993,200)$. Su identidad fue advenediza y su corazón un paria sufriente a lo largo de toda su vida.

\section{BIBLIOGRAFÍA}

Anders, Günther. 2013. La batalla de las cerezas. Mi historia de amor con Hannah Arendt. Barcelona: Paidós.

Arendt, Hannah. 1997. Rahel Varnhagen. The life of a Jewess. Baltimore: The Johns Hopkins University Press.

Arendt, Hannah. 2001. Hombres en tiempo de oscuridad. Barcelona: Editorial Gedisa, 
Arendt, Hannah. 2005. Ensayos de compresión 1930-1954. Trad. Agustín Serrano de Haro. Madrid: Caparrós Editores.

Arendt, Hannah. 2006. Los orígenes del totalitarismo. Madrid: Alianza Editorial.

Arendt, Hannah. 2016. La condición humana. Buenos Aires: Paidós

Arendt, Hannah y Karl Jaspers. 1993. Correspondence 1926 - 1969. Ed. Lotte Kohler y Hans Saner. Orlando: Harcourt Brace \& Company.

Bauman, Zygmunt. 2016. Extraños llamando a la puerta. Buenos Aires: Editorial Paidós.

Benhabib, Seyla. 2006. El ser y el otro en la ética contemporánea. Feminismo, comunitarismo y posmodernismo. Barcelona: Gedisa.

Boella, Laura. 2010. Pensar con el corazón. Hannah Arendt, Simone Weil, Edith Stein, María Zambrano. Madrid: Narcea S.A. de Ediciones.

Duby, Georges y Michelle Perrot comp. 2002. Histoire des femmes en Occident. IV. Le XIXe siècle. Paris: Editions Perrin.

Figueroa, Maximiliano. 2006. "Filosofía y dominación masculina. Aportes críticos de Enrique Dussel y Richard Rorty». Madrid: PENSAMIENTO, núm. 233: 345-354.

Godineau, Dominique. 2002. «Écrire et lire au féminin» Histoire des femmes en Occident. IV. Le XIXe siècle. Duby, Georges y Michelle Perrot comp. Paris: Editions Perrin.

Green, Nancy. 2002. "Les salonnières de Berlin» Histoire des femmes en Occident. IV. Le XIXe siècle. Duby, Georges y Michelle Perrot comp. Paris: Editions Perrin.

Hoock-Demarle, Marie-Claire. 2002. «Expressions. De l'écriture de soi à l'écriture pour les autres». Histoire des femmes en Occident. IV. Le XIXe siècle. Duby, Georges y Michelle Perrot comp. Paris: Editions Perrin.

Kant, Immanuel. 2015. Observaciones acerca del sentimiento de lo bello y lo sublime. Madrid: Alianza Editores.

Kristeva, Julia. 1999. Le génie féminin. Tome premier. Hannah Arendt. París: Librairie Arthème Fayard.

Rogers, Dorothy. 2000. Hegel and His "Victims" on Women in the Private Sphere. IWM Junior Visiting Fellow Conferences, vol. VI/1. Viena. Web 08 sep. 2017. http://www.iwm.at/publications/junior-visiting-fellows-conferences/vol-vi/hegel-and-his-victims-on-women-in-the-private-sphere/

Sánchez Muñoz, Cristina. 2003. Hannah Arendt. El espacio de la política. Madrid: Centro de Estudios Políticos y Constitucionales.

Venmans, Peter. 2015. El mundo según Hannah Arendt. Ensayos sobre su vida y obra. Córdoba: Eduvim.

Young-Brühl, Elisabeth. 2006. Hannah Arendt. Una biografía. Barcelona: Ediciones Paidós Ibérica S.A. 